Archives de sciences sociales des religions

112 | octobre-décembre 2000

Âme et corps : conceptions de la personne

\title{
MAYER (Arno), The Furies. Violence and Terror in the
} French and Russian Révolutions

Princeton, Princeton University Press, 2000, 716 p.

Michael Löwy

\section{OpenEdition}

\section{Journals}

Édition électronique

URL : http://journals.openedition.org/assr/20331

DOI : 10.4000/assr.20331

ISSN : $1777-5825$

Éditeur

Éditions de l'EHESS

Édition imprimée

Date de publication : 31 décembre 2000

Pagination : 108-109

ISBN : 2-222-96698-1

ISSN : 0335-5985

\section{Référence électronique}

Michael Löwy, "MAYER (Arno), The Furies. Violence and Terror in the French and Russian Révolutions »,

Archives de sciences sociales des religions [En ligne], 112 I octobre-décembre 2000, document 112.35,

mis en ligne le 19 août 2009, consulté le 21 septembre 2020. URL : http://journals.openedition.org/ assr/20331 ; DOl : https://doi.org/10.4000/assr.20331

Ce document a été généré automatiquement le 21 septembre 2020

(c) Archives de sciences sociales des religions 


\title{
MAYER (Arno), The Furies. Violence and Terror in the French and Russian Révolutions
}

Princeton, Princeton University Press, 2000, 716 p.

\author{
Michael Löwy
}

\section{RÉFÉRENCE}

MAYER (Arno), The Furies. Violence and Terror in the French and Russian Révolutions, Princeton, Princeton University Press, 2000, 716 p.

1 Ce livre frappe par l'intelligence des analyses, l'ampleur des vues, la pertinence de l'interprétation. Il s'agit d'une étude comparative, sans précédent par son envergure, de la violence et de la terreur dans les deux grandes révolutions modernes, la française et la russe.

2 Le titre choisi me semble problématique: si le mot "furies»- les déesses de la vengeance divine, dans la tragédie grecque ancienne (l'auteur mentionne Eschyle) exprime bien le caractère farouche et impitoyable du cycle de violence qui accompagne les révolutions, il a une connotation mythologique et archaïsante qui correspond mal à la modernité du phénomène étudié. Il risque de donner une coloration « anthropologique » à une démarche qui est, en fait, rigoureusement historiciste.

Une des idées fortes de l'auteur est l'inséparable lien entre la violence révolutionnaire et la violence contre-révolutionnaire: les deux se nourrissent, se renforcent et se propulsent réciproquement, dans une spirale ascendante que rien ne semble pouvoir arrêter. Cette approche lui permet d'éviter les interprétations apologétiques ou manichéennes, sans pour autant nécessairement renvoyer les deux camps dos à dos. Dans ce conflit violent, qui divise le champ politique en deux pôles irréconciliables, selon le schéma ami-ennemi étudié par Carl Schmitt, la religion joue un rôle non 
négligeable, en tant que facteur aggravant, qui intensifie, des deux côtés, le fanatisme et l'intolérance.

4 La «question religieuse » occupe donc une place importante dans l'analyse historique proposée par le livre. Selon l'A. la complicité entre le trône et l'autel, l'État et l'Église, rendait inévitable, aussi bien en France qu'en Russie, un choc frontal entre le projet révolutionnaire et l'institution religieuse. Il est difficile d'imaginer, observe-t-il, une question plus intraitable et plus provocatrice de division que la désacralisation et la laïcisation abruptes de la vie politique et sociale. En outre, les révolutions ont créé leur propre foi, une sorte de messianisme séculier à vocation universelle avec ses doctrines, ses mythes, ses rituels, ses martyrs, son calendrier. L'A. suit de près le passionnant débat entre Michelet et Quinet, et un siècle plus tard, entre Mathiez, Souboul et Reinhard sur le caractère religieux ou pas de la mystique révolutionnaire jacobine. En tout cas le conflit mobilisait des deux côtés des vrais croyants: les uns attachés à la nouvelle foi révolutionnaire, les autres à la religion du statu-quo (et plus tard, de la contre-révolution). Le même vaut, mutatis mutandis, pour la Révolution russe.

5 En France, le conflit entre la Révolution et l'Église est devenu brûlant à partir de 1790 avec la Constitution Civile du Clergé, déclenchant une véritable "guerre de religion ", qui nourrit et renforce la polarisation entre révolutionnaires et contrerévolutionnaires. Le Vatican joue un rôle important dans la crise, en adoptant une posture intransigeante, non seulement envers les décrets de l'Assemblée Constituante sur l'Église, mais aussi contre la «folie» de la liberté de pensée et d'expression, et contre la Déclaration des Droits de l'Homme et du Citoyen, négatrice des «droits de Dieu sur l'homme ». L'Église française se divise entre constitutionnels et réfractaires, mais les premiers, de tendance girondine, seront bientôt eux aussi mis en question par les sans-culottes. La campagne de dé-christianisa-tion de 1793-1794 impulsée à la fois par des initiatives locales spontanées et des mesures gouvernementales - calendrier républicain, culte de l'Être suprême - constitue un des sommets de cet affrontement violent et radical entre deux croyances opposées.

Le scénario russe, suite à la Révolution d'Octobre 1917, semble prendre le même chemin que le français un siècle et demi plus tôt. Face aux premiers décrets des commissaires du peuple bolchevicks - mariage civil, nouveau calendrier, nationalisation des terres et des écoles de l'Église orthodoxe - le Patriarche Tikhon lance en janvier 1918 l'anathème sur le régime des rouges (qu'il considère éphémère, comme beaucoup d'observateurs) et leur "œuvre de Satan». Le conflit s'aggrave encore plus en 1921 quand les bolchevicks, confrontés à la famine, exigent que l'Église fasse don de ses trésors pour financer l'importation de nourriture. Le synode en exil présidé par le Métropolite Antoine appelle à la restauration des Romanov et demande aux puissances occidentales de ne pas envoyer d'aide alimentaire à l'U.R.S.S. pour ne pas renforcer le pouvoir des rouges. Pendant que Tikhon est mis aux arrêts domiciliaires, une partie du clergé choisit, comme en France, le camp révolutionnaire et fonde "l'Église Vivante », qui prône l'abolition du Patriarcat et la démocratisation de l'institution.

7 Même si le facteur religieux joue un certain rôle dans la guerre civile entre "rouges » et «blancs", l'affrontement ne prendra pas les mêmes proportions qu'en France: on assiste, des deux côtés, à un désir pragmatique de desescalade. Tandis que Lénine, au plus fort du conflit, insiste sur la nécessité de « ne pas heurter les sentiments religieux des croyants » parce que ceci «ne servirait qu'à renforcer le fanatisme religieux », le 
Patriarche Tikhon, libéré des arrêts domiciliaires après la victoire de l'Armée Rouge dans la guerre civile, finit par se rallier au nouveau régime (juin 1923).

Comment expliquer le caractère relativement moins violent et moins intransigeant du conflit entre l'Église et la Révolution en Russie, comparé avec l'exemple français ? Cela est d'autant plus étonnant que la culture des révolutionnaires russes était beaucoup plus marquée par un athéisme militant que celle des jacobins français. Est-ce parce que les paysans russes se méfiaient du haut clergé, trop identifié à l'Ancien Régime, comme le suggère l'A. ? L'hypothèse est intéressante mais demande elle-même une explication, et en tout cas n'est pas suffisante pour rendre compte de la notable différence entre les deux révolutions, en ce qui concerne le rôle du facteur religieux dans le conflit.

Dans un chapitre séparé, l'A. examine, sous le titre «dangers de l'émancipation », la situation des minorités religieuses au cours de la tempête révolutionnaire: les protestants français d'une part, les juifs de l'Empire russe de l'autre. Si dans le long terme les révolutions sont bénéfiques pour ces minorités opprimées, dans le court terme elles sont assez dangereuses, dans la mesure où ces groupes apparaissent comme le bouc expiatoire idéal pour les peurs et les ressentiments provoqués par le changement social radical et sont désignés par les idéologues de la contre-révolution comme les principaux responsables d'une conspiration diabolique pour renverser les institutions.

Malgré l'agitation anti-protestante du catholicisme royaliste et quelques affrontements locaux - les «bagarres » de Montauban et Nîmes - on ne peut pas parler d'une attaque massive contre les disciples de Luther ou Calvin. Par contre, dans le cas russe, les juifs, étroitement associés au communisme dans l'imaginaire contre-révolutionnaire, ont été victimes de pogroms à grande échelle, faisant entre 60 et 150000 morts. Un mélange d'antijudaïsme traditionnel - d'inspiration religieuse - et d'antisémitisme politique moderne a motivé ces massacres, menés par les chefs locaux cosaques ou les généraux des Armées blanches.

11 On se trouve ici confronté à un paradoxe (non discuté par l'A.) : c'est dans la révolution où le facteur religieux a joué un rôle relativement moindre, que la persécution d'une minorité religieuse (par les contre-révolutionnaires) a été la plus violente et meurtrière.

12 Cette recherche laisse - inévitablement! - un certain nombre de questions sans réponse, mais elle ne constitue pas moins un apport d'une valeur exceptionnelle à l'historiographie des révolutions modernes. 